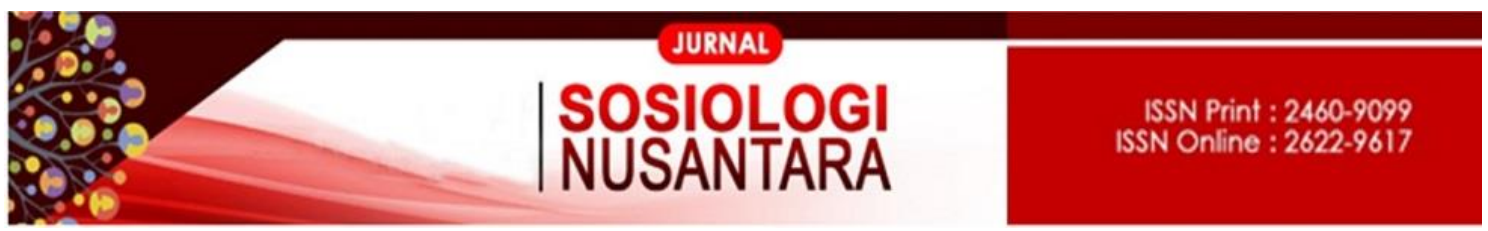

https://ejournal.unib.ac.id/index.php/jsn

DOI ://doi.org/10.33369/jsn.4.2.98-104

\title{
ANALISIS PERILAKU ASERTIF PUSTAKAWAN DI BAGIAN LAYANAN PERPUSTAKAAN UIN RADEN FATAH PALEMBANG
}

\author{
ANALYSIS OF ASERTIF BEHAVIOR OF LIBRARIANS \\ AT THE LIBRARY SERVICES UIN RADEN FATAH PALEMBANG
}

\author{
Budhi Santoso \\ kangbudhi_uin@radenfatah.ac.id \\ Universitas Islam Negeri Raden Fatah, Palembang
}

\begin{abstract}
Abstrak
Perilaku asertif merupakan salah satu hal yang sangat penting dimiliki pustakawan dalam membina hubungan interpersonal saat melakukan pelayanan. Perilaku asertif merupakan salah satu cara komunikasi yang terkait dengan ekspresi perasaan, pikiran secara langsung, jujur dan terbuka. Hal ini sesungguhnya menyangkut komunikasi verbal dan non verbal. Penelitian ini bertujuan untuk menganalisis Perilaku asertivitas pustakawan di bagian layanan Perpustakaan UIN Raden Fatah Palembang. Jenis penelitian ini adalah deskriptif dengan menggunakan pendekatan kuantitatif adapun teknik pengumpulan data menggunakan kuesioner yang terdiri dari 17 pernyataan positif dengan metode purposive sampling. Sampel yang diambil sebanyak 5 orang responden dibagian layanan Perpustakaan UIN Raden Fatah. Analisis deskriptif yang digunakan untuk menganalisis data adalah mean dan grand mean. Hasil penelitian menunjukkan bahwa Tingkat asertif staf perpustakaan UIN Raden Fatah Palembang memperoleh grand mean 3,5 Nilai tersebut berada pada rentang skala 3,40 - 4,20 yang menunjukkan bahwa tingkat asertif staf perpustakaan UIN Raden Fatah berada pada tingkat tinggi. Indikator yang perlu ditingkatkan yaitu Mengajukan Hak memperoleh nilai 2,8 Nilai tersebut berada pada rentang skala 2,60-3,40 berada pada tingkat sedang dan ungkapan perasaaan memperoleh nilai 2,2 Nilai tersebut berada pada rentang 2,603,40 berada pada tingkat sedang.
\end{abstract}

Kata Kunci : asertif, pustakawan asertif, pelayanan asertif

\section{Abstract}

The behavior of assertive is one of the very important thing owned librarians in building interpersonal relationships while performing service. The behavior of asertif is one of the ways of communication associated with the expression of feelings, minds directly, honestly and openly. This surely comes to verbal and non-verbal communication. This research aims to analyze the behavior of asertivitas librarians at 
the library services UIN Raden Fatah Palembang. Type of this research is descriptive using the quantitative approach with regard to data collection techniques using a questionnaire consisting of 17 positive statement with the method of purposive sampling. Samples taken as many as five people in the library service respondents UIN Raden Fatah. descriptive analysis was used to analyze the data are mean and the grand mean. The results showed that the level of the library staff assertive gained a grand mean 3.5 Value the range of $3.40-4.20$ scale that indicates that the level of the library staff asertif UIN Raden Fatah is at a a high level. Indicators needs to be improved, namely Filing Rights gain value is the value of 2.8 range scale 2.603 .40 - is at the level of the medium and expression of perasaaan acquire the value of 2.2 is at the range of $2.603 .40-i$ at the level of being.

Keywords : assertive, assertive librarian, assertive service

\section{PENDAHULUAN}

Perpustakaan perguruan tinggi mempunyai fungsi sebagai penunjang tri darma perguruan tinggi yaitu (pendidikan, penelitian dan pengabdian masyarakat) Menurut Noerhayati (1987:1), "perpustakaan perguruan tinggi adalah suatu unit kerja yang merupakan bagian integral dari suatu lembaga induknya yang bersama-sama unit lainnya tetapi dalam peranan yang berbeda, bertugas membantu perguruan tinggi yang bersangkutan melaksanakan Tri Dharmanya". Sebagai penunjang perguruan tinggi perpustakaan mempunyai peran dalam melayani sivitas akademika terutama dalam memperoleh informasi yang dibutuhkan pemustaka dalam membatu perkuliahan. Ketika melayani pustakawan tidak dapat dilepaskan dengan adanya interaksi sosial, salah satu interaksi yaitu komunikasi. Pustakawan yang memiliki keterampilan komunikasi yang baik, akan memberikan kepuasan professional dalam melayani serta meningkatkan citra profesi pustakawan dan perpustakaan, memudahkan pustakawan untuk menjalin hubungan rasa percaya baik kepada pemustakanya.

Komunikasi agar dapat berjalan efektif, maka seorang pustakawan perlu menampilkan tingkah laku asertif. Perilaku asertif adalah keterampilan untuk mencari, mengelola dan mengembangkan keterampilan interpersona melalui ekspresi perasaan atau keinginan ketika ekspresi tersebut dapat mengurangi resiko penguatan negatif (seperti ketidaksukaan) derajat asertivitas diukur dari seberapa efektif individu tersebut merespon dan mengelola stimulus yang ada (Savitri and Efendi 2011:4). Pustakawan yang memiliki asertivitas lebih mudah untuk bekerja sama dan dapat berkembang untuk mencapai tujuan bersama. 
Perilaku asertif sangatlah penting dimiliki oleh seorang pustakawan karena beberapa alasan berikut : pertama, dengan kemampuan untuk mengungkapkan apa yang dirasakan dan diinginkan secara langsung dan terus terang bisa menghindari munculnya konflik; kedua, bila ada rekan kerja maupun atasan yang bersikap atau berperilaku kurang tepat pustakawan bisa mengingatkannya dengan komunikasi yang berperilaku asertif; ketiga, dengan memiliki perilaku asertif maka pustakawan dapat dengan mudah mencari solusi penyelesaian dari berbagai kesulitan maupun permasalahan secara efektif; dan alasan yang terakhir, dengan berperilaku asertif dapat membantu meningkatkan kemampuan kognitif pustakawan dengan berdiskusi dengan rekan kerja. Jadi, keasertifan diri bukanlah sikap pasif yang memperkuat persetujuan atau penolakan dan juga bukan sikap agresif yang dapat mengintimidasi orang lain.

Perilaku asertif merupakan keterampilan sosial (social skill) yang harus dimiliki dan akan membantu pustakawan dalam menghadapi berbagai karakter pengguna. Salah satu aspek ketrampilan sosial yang sangat tepat dimiliki pustakawan adalah perilaku asertif. Perilaku yang asertif akan menghasilkan hubungan yang harmonis antara pustakawan dan pengguna, dimana masing-masing pihak dapat saling memahami dan menghargai sehingga lebih memudahkan untuk memecahkan suatu permasalahan.

Berdasarkan latar belakang di atas maka peneliti tertarik untuk meneliti Perilaku asertivitas pustakawan di bagian layanan UPT Perpustakaan UIN Raden Fatah Palembang.

\section{METODE PENELITIAN}

Penelitian ini termasuk jenis penelitian kuantitatif. Metode penelitian kuantitatif merupakan metode penelitian yang digunakan untuk meneliti pada populasi dan sampel tertentu, pengumpulan data menggunakan instrumen penlelitian, analisis data bersifat kuantitatif/statistik, dengan tujuan untuk menguji hipotesis yang telah ditetapkan (Sugiyono 2013:8)

Populasi dalam penelitian ini adalah pustakawan yang bertugas dibagian sirkulasi di Perpustakaan UIN Raden Fatah Palembang yang berjumlah 5 orang. Karena jumlahnya relatif sedikit, maka peneliti putuskan untuk melakukan penelitian popluasi atau menggunakan teknik sampling jenuh. Sampling jenuh dilakukan jika jumlah populasi relatif sedikit (Sugiyono 2013:85). Teknik pengumpulan data yang digunakan 
yaitu kuesioner, observasi, wawancara, dan dokumentasi. Data kemudian dianalisis menggunakan rumus mean, Adapun rumus mean adalah sebagai berikut :

$$
\mathrm{X}=\frac{\sum \mathrm{X}}{\mathrm{N}}
$$

Keterangan:

$\mathrm{X}=$ Mean (rata-rata)

$\sum \mathrm{X}=$ Jumlah jawaban penjumlahan semua responeden

$$
\mathrm{N}=\text { Banyaknya unit/bilangan (Arikunto 2010:315) }
$$

Setelah diketahui rata-rata dari jawaban responden, lalu dilakukan perhitungan menggunakan rumus grand mean untuk mengetahui rata-rata umum dari masing-masing butir pernyataan. rumus grand mean adalah sebagai berikut: Grand Mean $(\mathrm{X})=\frac{\text { Total rata }- \text { rata hitung }}{\text { Jumlah pernyataan }}$

Untuk mencari rentang skala dari jawaban responden menggunakan rumus di bawah ini:

$$
\mathrm{RS}=\frac{\mathrm{m}-\mathrm{n}}{\mathrm{b}}
$$

Keterangan:

$\mathrm{RS}=$ Rentang Skala

$\mathrm{m}=$ Skor tertinggi

$\mathrm{n}=$ Skor terendah

$\mathrm{b}=$ Skala penilaian (Arikunto 2010:315) .

Maka perhitungan rentang skalanya sebagai berikut:

$$
\begin{aligned}
\mathrm{RS} & =\frac{\mathrm{m}-\mathrm{n}}{\mathrm{b}} \\
\mathrm{RS} & =\frac{5-1}{5} \\
\mathrm{RS} & =\frac{4}{5}
\end{aligned}
$$

$$
\mathrm{RS}=0,80(\text { Simamora 2008:220) }
$$

Sehingga rentang skalanya adalah 0,80 , dengan rentang skala 0,80 kemudian dibuat skala penilaian sebagai berikut:

$$
\begin{aligned}
& 1,00-1,80=\text { Sangat Rendah } \\
& 1,80-2,60=\text { Rendah } \\
& 2,60-3,40=\text { Sedang }
\end{aligned}
$$




$$
\begin{aligned}
& 3,40-4,20=\text { Tinggi } \\
& 4,20-5,00=\text { Sangat Tinggi }
\end{aligned}
$$

\section{PEMBAHASAN}

Peneliti menyebarkan kuesioner kepada 5 responden yang ada di pelayanan sirkulasi dengan jumlah pernyataan 17 butir. Pertanyaan itu terdiri dari satu variabel asertif pustakawan dibagian layanan UPT UIN Raden Fatah Palembang. Berikut ini merupakan hasil akhir dari penghitungan menggunakan rumus mean dan grand mean.

Tabel 1 Jawaban Responden Tentang Perilaku Asertif

\begin{tabular}{|c|c|c|c|c|c|}
\hline No & Sub variabel & Indikator & Nilai Rata-Rata & Kategori & $\begin{array}{l}\text { Total Nilai } \\
\text { Rata-Rata }\end{array}$ \\
\hline 1 & \multirow{6}{*}{ Verbal } & Kekerasan Suara & 3,7 & Tinggi & \multirow{6}{*}{3,8} \\
\hline 2 & & Kelancaran & 4,2 & Sangat Tinggi & \\
\hline 3 & & Kontak Mata & 4,4 & Sangat Tinggi & \\
\hline 4 & & Ungkapan Wajah & 3,6 & Tinggi & \\
\hline 5 & & Ungkapan Tubuh & 3,4 & Tinggi & \\
\hline 6 & & Jarak & 3,8 & Tinggi & \\
\hline
\end{tabular}

Sub Variabel Verbal

Berdasarkan tabel di atas diketahui komunikasi verbal sebagai unsur perilaku asertif dibagi menjadi 6 indikator, dimana indikator tersebut dipresepsikan mempunyai tingkat komunikasi yang tinggi. Perbandingan indikator komunikasi verbal dapat di lihat pada grafik di bawah ini :

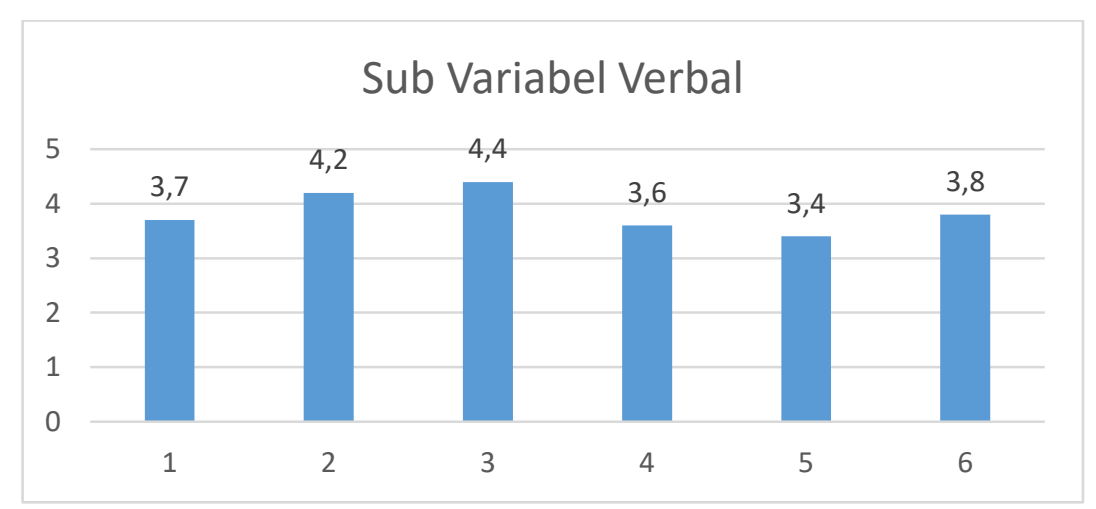

Gambar 1. Diagram analisis indikator subvariabel verbal 
Berdasarkan grafik di atas, menunjukan bahwa 6 indikator untuk variabel verbal diperoleh rata-rata 3,8 dengan kategori tinggi. Nilai tertinggi dapat dilihat dari indikator kontak mata sedangkan nilai terendah terlihat pada indikator kekerasan suara.

Tabel 2 Jawaban Responden Tentang Perilaku Asertif

Sub Variabel Non Verbal

\begin{tabular}{|c|c|c|c|c|c|}
\hline No & $\begin{array}{c}\text { Sub } \\
\text { Variabel }\end{array}$ & Indikator Asertif & $\begin{array}{c}\text { Nilai Rata- } \\
\text { Rata }\end{array}$ & Kategori & $\begin{array}{l}\text { Total Nilai } \\
\text { Rata-Rata }\end{array}$ \\
\hline 1 & \multirow{5}{*}{ Non Verbal } & Mengatakan tidak & 4,2 & Tinggi & \multirow{5}{*}{3,2} \\
\hline 2 & & $\begin{array}{c}\text { Menunjukkan } \\
\text { sikap }\end{array}$ & 3,3 & Sedang & \\
\hline 3 & & $\begin{array}{l}\text { Meminta } \\
\text { Pertolongan }\end{array}$ & 3,5 & Sedang & \\
\hline 4 & & Mengajukan Hak & 2,8 & Rendah & \\
\hline 5 & & $\begin{array}{l}\text { Ungkapan } \\
\text { Perasaan }\end{array}$ & 2,2 & Rendah & \\
\hline
\end{tabular}

Berdasarkan tabel di atas diketahui komunikasi non verbal sebagai unsur perilaku asertif dibagi menjadi 5 indikator, dimana indikator tersebut dipresepsikan mempunyai tingkat komunikasi non verbal yang sedang. Perbandingan indikator komunikasi non verbal dapat di lihat pada grafik di bawah ini :

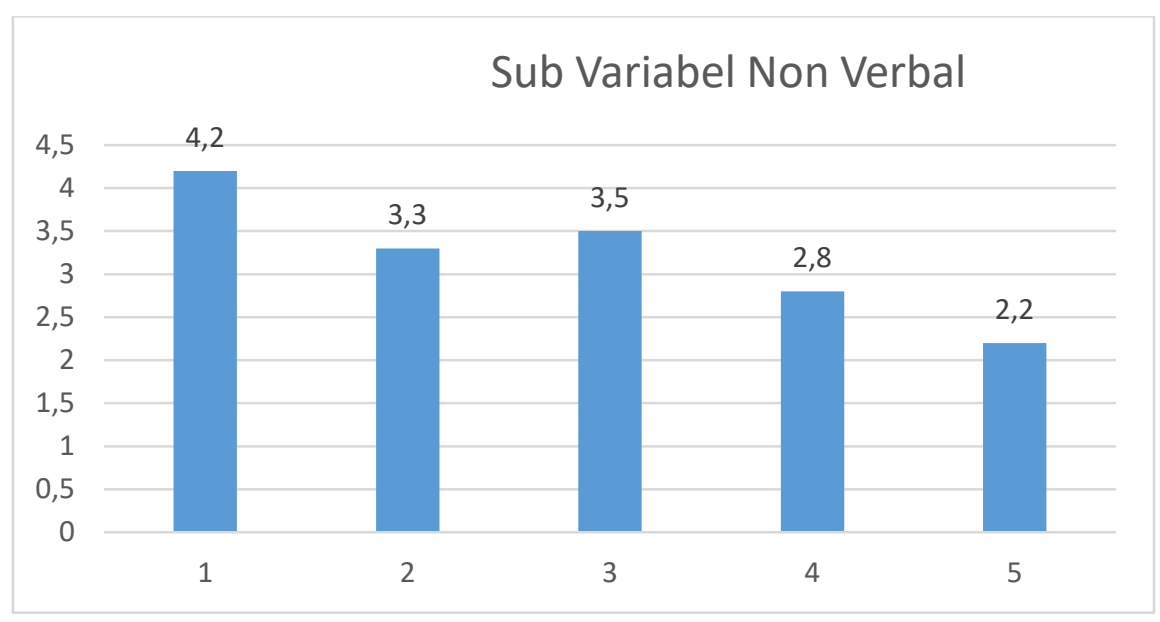

Gambar 2. Diagram analisis indikator subvariabel non verbal

Berdasarkan grafik di atas, menunjukan bahwa 5 indikator untuk sub variabel non verbal diperoleh rata-rata 3,2 dengan kategori sedang. Nilai tertinggi dapat dilihat 
dari indikator mengatakan tidak sedangkan nilai terendah terlihat pada indikator ungkapan perasaan.

\section{KESIMPULAN}

Berdasarkan hasil analisis penelitian di atas, dapat disimpulkan sebagai berikut :

1. Tingkat asertif staf perpustakaan UIN Raden Fatah Palembang memperoleh grand mean 3,5 Nilai tersebut berada pada rentang skala 3,40 - 4,20 yang menunjukkan bahwa tingkat asertif staf perpustakaan UIN Raden Fatah berada pada tingkat tinggi.

2. Indikator yang perlu ditingkatkan yaitu Mengajukan Hak memperoleh nilai 2,8 Nilai tersebut berada pada rentang skala 2,60 - 3,40 berada pada tingkat sedang dan ungkapan perasaaan memperoleh nilai 2,2 Nilai tersebut berada pada rentang 2,60 - 3,40 berada pada tingkat sedang.

\section{DAFTAR PUSTAKA}

Arikunto, Suharsimi. 2010. Prosedur Penelitian: Suatu Pendekatan Praktik. Rineka Cipta.

S, Noerhayati. 1987. Pengelolaan Perpustakaan Jilid I. Bandung: Alumni.

Savitri, Intan and Siddik Efendi. 2011. Kenali Komunikasi. Jakarta: Balai Pustaka.

Simamora, Bilson. 2008. Panduan Riset Perilaku Konsumen. Jakarta: Gramedia Pustaka Utama.

Sugiyono. 2013. Metode Penelitian Pendidikan Pendekatan Kualitatif, Kuantitatif, Dan $R \& D$. Jakarta: Alfabeta. 